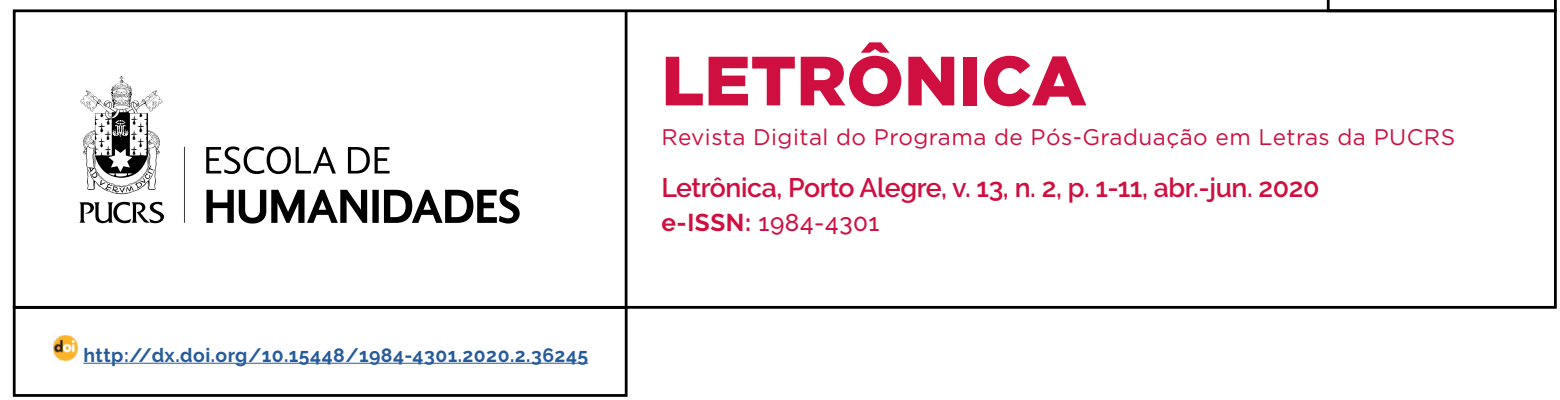

\title{
Reflexões sobre leitura e ensino no Brasil em tempos de pós-verdade
}

\author{
Reflections on reading and teaching in post-truth times
}

\section{Ilmara Valois B F \\ Coutinho ${ }^{1}$ \\ orcid.org/0000-0002-5286-5618 \\ ilmaravalois@hotmail.com}

Publicado em: 13 ago. 2020.

\begin{abstract}
Resumo: O presente texto busca realizar uma reflexão acerca da leitura, considerando-a no bojo de uma contemporaneidade representada por incertezas, por alterações vertiginosas na produção, circulação e consumo de informações e conhecimentos, o que coloca a formação leitora à frente de um grande desafio. Em tempos de pós-verdade, com perseguições, interdições, precarização do trabalho dos profissionais e das estruturas físicas das instituições públicas em todos os niveis da educação do País, a escola é um importante flanco de resistência, ao preparar crianças e jovens para lidarem criticamente com as textualidades vertiginosas apresentadas cotidianamente e que, não raro, disseminam discursos intolerantes que podem ser consumidos com a mesma velocidade com que circulam nas redes sociais. Nessa perspectiva, defende-se, no presente texto, o ensino da leitura como ato político que pode gerar pensamento crítico frente às contradições sociais, oportunizando que as novas gerações circulem com maior facilidade no expandido campo das linguagens entrecruzadas da contemporaneidade, inclusive aquelas provenientes das tecnologias digitais.

Palavras-chave: Leitura. Pós-verdade. Identidade. Ensino.
\end{abstract}

Abstract: The present text seeks to make a reflection about reading, considering it in the bulge of a contemporaneity represented by uncertainties, by vertiginous changes in the production, circulation and consumption of information and knowledge, which puts the reader formation ahead of a great challenge. In post-truth times, with persecution, interdiction, precarious work of professionals and the physical structures of public institutions at all levels of education in the country, the school is an important flank of resistance in preparing children and youth to deal critically with the dizzying textualities presented daily to be consumed at the same speed as they circulate in social networks. From this perspective, this text defends the teaching of reading as a political act that can generate critical thinking in the face of social contradictions, enabling the new generations to circulate more easily in the expanded field of contemporary cross-languages, including those from digital technologies and the fight against intolerant speeches. Keywords: Reading. Post truth. Identity. Teaching.

\section{Introdução}

O presente texto busca realizar uma reflexão acerca da leitura, considerando-a no bojo de uma contemporaneidade representada por incertezas, por alterações vertiginosas na produção, na circulação e no consumo de informações e conhecimentos, sendo testemunha de um tempo instado a tornar tudo disponivel a todos, sem poder garantir qualquer veracidade à palavra dita, escrita, enunciada, a priori. Nessa perspectiva, entende-se ser necessário potencializar o ensino da leitura em seus diferentes modos de realização, enquanto ato político capaz de preparar crianças e jovens para transitarem, com menos 
dificuldades, no expandido campo das linguagens entrecruzadas e das tecnologias digitais, sendo também possibilidade de compreensão acerca dos discursos intolerantes que precisam ser combatidos, porquanto têm servido à perseguição das diferenças, sejam elas linguísticas, étnicas, de gênero, políticas.

Há uma constatação inquietante em torno dos sentidos que a leitura tem suscitado na contemporaneidade no Brasil, pois o trabalho pedagógico oferecido nos bancos escolares tem ainda um caminho longo a seguir no sentido de garantir amplo acesso da população a esse bem indispensável à cidadania, situação que têm sido assinalada por pesquisas que aferem a proficiência leitora dos brasileiros. Segundo a última edição do Programa Internacional de Avaliação de Estudantes (Pisa), o Brasil continua demonstrando baixo desempenho em leitura, tendo em vista que $50 \%$ dos brasileiros não atingiram o mínimo de proficiência para o final do ensino médio, resultado que, "provavelmente, representa um grande obstáculo na vida desses jovens, dificultando ou até mesmo impedindo que avancem em seus estudos, tenham oportunidades melhores no mercado de trabalho e participem plenamente da sociedade" (INEP, 2018, p. 69-90). O fato é endossado pelo Indicador de Alfabetismo Funcional (INAF), ao destacar que cerca de $3 \mathrm{em}$ cada 10 brasileiros "têm muita dificuldade para fazer uso da leitura e da escrita e das operações matemáticas em situações da vida cotidiana [...], sendo considerados analfabetos funcionais (INSTITUTO PAULO MONTENEGRO, 2018, p. 8).

Nessa perspectiva, pode-se considerar que as desigualdades na proficiência leitora (persistência de um grande número de analfabetos funcionais) no Brasil são também fruto de desigualdades sociais gritantes que fazem a leitura, entendida de forma ampla, concretizar-se como privilégio restrito às classes mais favorecidas (SOARES, 2017), representando fator preponderante de poder e ascensão social para as mesmas, enquanto a maioria dos "alfabetizados" continua excluída do mundo da escrita, um mundo que supõe espaços privilegiados, caracterizados por discursos e referências especificas, por expressões etnocêntricas de cultura e valor, o que reforça a necessidade de a escola firmar-se como "agência de democratização dos letramentos" (ROJO; MOURA, 2019, p. 17).

Enquanto universo educativo para onde convergem contradições políticas, sociais, culturais e econômicas, a escola tem o compromisso de promover uma práxis pedagógica inclusiva - ou menos excludente de leitura, otimizando sua potencialidade formadora de representações e identidades que podem ser problematizadas por diversos modos, materiais e lugares interpretativos, ainda que tenhamos que reconhecer a existência constante de forças repressoras agindo sobre a sua competência, a exemplo das recentes tentativas de censura direcionadas a livros de literatura. ${ }^{2}$

Isso porque, salvaguardando-se concepções estereotipadas e normativas, a leitura amplia a visão de mundo dos sujeitos, fornecendo armas discursivas potentes no enfrentamento da vocação dominadora de uma parcela privilegiada da sociedade em relação às chamadas minorias, inclusive, tornando possivel a suspeição das muitas formas de "cinismo" a que estão submetidos os textos e discursos na atualidade, para lembrar Sloterdijk (2012, p. 31), ao asseverar que "A sequência de formas de falsa consciência até agora - mentira, erro, ideologia - está incompleta; a mentalidade atual força o acréscimo de uma quarta estrutura - a do fenômeno cinico". Trago o fenômeno cinico compreendendo-o como partícipe estruturante de construções discursivas que jogam com as verdades para convencer e manter o status quo de uma sociedade claramente elitista e interessada em manipular opiniões. Nesse

\footnotetext{
2 Refiro-me às tentativas de censura que têm acontecido recentemente no País, como foi possivel constatar na notícia de que o governo de Rondônia havia preparado uma lista de livros a serem proibidos nas escolas do estado, por sua suposta "inadequação". Embora a proibição não tenha se concretizado, segundo o que foi noticiado, não se pode dizer que essa tenha sido uma ação isolada. Disponível em: https://brasil.elpais.com/brasil/2020-02-08/censura-de-livros-expoe-laboratorio-do-conservadorismo-em-rondonia.html. Acesso em: 2 abr. 2020
} 
cenário, uma necessária compreensão crítica de leitura, como já destacou Freire (2004, p. 11), pressupõe considerá-la em sua potencialidade efetiva de politização no combate à ignorância, à exploração e à exclusão, podendo ser condição de inserção e de participação social, "instrumento de luta contra a dominação".

Entende-se que seja condição precipua de humanização a luta contra a opressão, o direito à palavra. Como ressalta Freire (2011, p. 44), "Não é no silêncio que os homens se fazem, mas na palavra [...]", principalmente para quem vêm sofrendo imposições hegemônicas ainda bem firmes no presente, como podemos atestar facilmente por meio de propostas político-governamentais para a educação, a exemplo do Projeto Escola sem Partido, ${ }^{3}$ claramente destinado a estabelecer a interdição de variados discursos nas escolas do País e que, deixando de tematizar questões imprescindiveis como acesso, permanência e qualidade do ensino, pregam a demonização do que chamam de ideologia de gênero; incentivam a perseguição a professores/intelectuais acusados de "doutrinadores esquerdistas" e caracterizados como partidários; promovem a defesa acalorada de propostas que em nada parecem acrescentar ao desenvolvimento da educação, estabelecendo limites populistas e ineficazes, com base no velho discurso do preconceito, da desinformação, da ignorância.

Nesse contexto, a leitura é solicitada a realizarse por meio uma práxis pedagógica cônscia do seu papel político frente às demandas do presente, assegurando que as identidades, fruto de batalhas travadas em ambiências socioculturais diversas, encontrem práticas de letramento condizentes com o seu amplo desenvolvimento, como já presenciamos a partir das ações dos movimentos GLBTQl+, das organizações que tratam de identidade de gênero, de etnia ou de raça, da emergência de vozes em contextos periféricos, que seguem imprimindo linguagens diferenciadas no universo dos dizeres, fazendo circular, mesmo no vigiado ambiente escolar, textos outrora impensáveis para a nossa sociedade tão desejosa de ordenação excludente. Enquanto possibilidade de representação e representatividade, as práticas leitoras escolares, para além dos determinantes individuais do sujeito, também precisam abarcar seu pertencimento grupal, comunitário, cultural, fazendo da linguagem mediação simbólica instada a assegurar trocas e partilhas no incerto burburinho discursivo de uma atualidade marcada por ares de pós-verdade.

É forçoso reconhecer que o desenvolvimento de novos processos de significação e sistemas simbólicos tem exigido da educação reordenações instadas a colocar o ensino da leitura em posição cada vez mais estratégica, no sentido de propiciar ferramentas de locomoção nesse terreno movediço que sustenta a construção dos sentidos na contemporaneidade e suas rajadas fakes de teorização do cotidiano. Formar leitores capazes de estabelecer uma relação dialógica e crítica com o mundo, com condições de confrontar as múltiplas vozes que permeiam os textos socialmente, é fazer vivenciar a leitura como movimento ad infinitum que "se antecipa e se alonga na inteligência do mundo", como nos disse Paulo Freire (2004, p. 11).

\section{Identidade leitora: onde os (in)essenciais?}

Apenas muito recentemente avançamos em áreas como alfabetização, letramento, compreensão de textos e discursos, muitas vezes, em seu nivel mais elementar, mas o que vemos hoje é a solicitação de que o trabalho pedagógico dê um salto tão grandioso quanto aqueles dados pelo desenvolvimento das tecnologias, num cenário cada vez mais subfinanciado, ${ }^{4}$ por uma agenda governamental que pretende gerar avanço educacional partindo 
de retrocessos metodológicos ${ }^{5}$ e precarização do trabalho dos profissionais e das estruturas físicas das instituições públicas, em todos os niveis da educação do país, o que claramente é um contrassenso.

Em tal cenário, intensificam-se entendimentos controversos acerca de quem pode ter pleno acesso aos bancos educacionais e a niveis mais avançados de formação, assim como é possivel antever uma preocupação premente acerca da formação de uma mão de obra qualificada pelo imediatismo. Não é difícil asseverar que as políticas contemporâneas esperam que o cidadão comum tenha uma formação leitora mediana, que possa ingressar cada vez mais cedo no mercado de trabalho e, para isso, unem-se forças econômicas e políticas que pregam um retrocesso capaz de fazer pensadores como Paulo Freire ${ }^{6}$ serem execrados em passeatas e redes sociais, logicamente, fazendo reverberar uma antiga predisposição de membros das classes médias e das elites do País para limitar o acesso ao conhecimento, ao livro, à leitura. Considerando que a história, em muitos aspectos, segue um movimento cíclico, podemos antever a continuidade de um retrato limitado para a identidade leitora da maioria dos cidadãos brasileiros, posto que a democratização do acesso a bens culturais diversos (livros, jornais, museus, cinemas) continua decisivamente ligado a poucos, o que está refletido nos dados publicados recentemente pelo INAF (INSTITUTO, 2018).

Os inessenciais à educação, para tomar um termo usado por Beauvoir (1970) para a mulher e que se adequa a várias categorias tomadas na contramão do que é considerado essencial, jamais pensados quando o assunto é o acesso a um ensino de qualidade, podem estar submetidos, no mercado da formação limitadora e do consumo rápido das linguagens, a formas e materiais leitores prioritariamente fornecidos pelas mídias, esse território "do disponivel e do transitório" (CANCLINI, 2008, p. 26), onde circulam verdades parciais e convenientes, o que precisa ser considerado como ponto fundamental no trabalho pedagógico das escolas interessadas em propiciar experiências leitoras significativas à ampliação do conhecimento acerca dos discursos e suas implicações. Vive-se atualmente um cotidiano atravessado por textualidades intensas, velozes, pouco confiáveis, o que pode nos levar, como nos lembra Tiburi (2017, p. 116), a deixar passar "a chance de compreender", quando a primeira oferta no mercado das ideias parece adequada, sendo consumida sem maiores reflexões.

Historicamente, o projeto oficial da cultura brasileira firmou-se na invisibilidade, ou mesmo na total ausência, de pobres, negros, indigenas, jovens de periferia, fazendo reverberar uma construção discursiva geradora de intolerâncias fundadas entre "o capitalismo (desigualdade social), o colonialismo (discriminação racial) e o patriarcado (discriminação sexual)", exclusões mantidas ainda hoje, como nos chama a atenção Boaventura Sousa Santos (2018, p. 14). Nessa empreitada, a grande maioria da população brasileira teve suas vozes apagadas por diferentes estratégias, tornando-se "invisiveis para a história" (MC LAREN, 1997, p. 255), sem poder moldá-la ou mesmo integrá-la como sujeitos leitores e produtores dos textos componentes do seleto meio intelectual, educacional ou acadêmico.

Conforme Márcia Abreu (2001), ao discutir o preconceito em leitura, enquanto cultuarmos uma leitura idealizada, corremos o risco de não enxergar o que está posto nas relações cotidianas, concretizando um processo sutil de naturalização de uma "violência simbólica", nas palavras de Bourdieu (2001), que elegeu uma maneira "correta" para ler, como também selecionou os materiais de leitura a serem valorizados, estabelecendo um parâmetro homogeneizador, estereotipado,

\footnotetext{
5 Além dos cortes nos orçamentos, também há métodos de ensino adotados sob forte crítica de estudiosos da área. Ver entrevista com Magda Soares acerca da política de alfabetização adotada pelo MEC. Disponivel em: https://desafiosdaeducacao.grupoa.com.br/ magda-soares-alfabetizacao-saeb/. Acesso em: 3 abr. 2020.

6 Durante as manifestações de protesto contra a presidenta Dilma, ainda em 2015, chamou a atenção uma faixa com a seguinte construção: "Chega de doutrinação marxista/basta de Paulo Freire". Além disso, foram muitas as manifestações contra Paulo Freire, incluindo a retirada de seu nome da Plataforma Freira, denominada, em 2019, "Plataforma da Educação Básica" e Projeto de Lei, na Câmara dos Deputados, para revogação do título de Patrono da Educação Brasileira, concedido em 2012.
} 
xenofóbico e discriminador em relação ao qual todas as outras realizações leitoras estavam hierarquizadas. O problema que se coloca é a (não)possibilidade de identificação que a leitura suscita na maioria das pessoas que não dispõem das condições historicamente associadas ao leitor. Há um não-dito fundamental nessa forma de representação que estabelece claramente quem pode e quem não pode ler, embora o discurso a favor da democratização da leitura esteja presente em todos os espaços sociais, o seu exercício torna-se extremamente excludente.

Mesmo na contemporaneidade, quando podemos contabilizar uma intensificação inédita na produção e circulação de escritos, o apagamento das leituras desenvolvidas nas ruas e casas da maioria dos brasileiros, é recorrente, tornando invisivel a franca existência de modos e materiais constantes das relações cotidianas de leitura e escrita. Também podemos constatar a permanência, e até uma intensificação nos últimos anos, de uma interdição já bem conhecida da história da leitura e que se apraz em determinar o malefício de materiais que tratam de temas ditos indesejados para a educação das crianças e jovens, ainda que em nada possam ser de fato questionados, mas que tocam em pontos que a sociedade está mais disposta a sufocar e apagar, como o que ocorreu com alguns textos presentes na prova do Exame Nacional do Ensino Médio ENEM 2018, acusados, entre outras coisas, de tratar da tão propalada ideologia de gênero, o que fez com que o exame fosse alvo de críticas pelo próprio presidente da república. ${ }^{7}$

Faz-se necessário reconhecer que o poder de representar guarda também o poder de determinar e, como nos diz Bourdieu (2001, p. 233-234), "Historicizar nossa relação com a leitura é uma forma de nos desembaraçarmos daquilo que a história pode nos impor como pressuposto inconsciente"; assertiva que evidencia um caminho relevante para a leitura em muitas instâncias, porquanto possibilita a não aceitação de pressupostos edificados por uma história que favoreceu a poucos e que, revisitada, tem sido fonte de fortalecimento para muitas das categorias excluias do retrato da leitura no Brasil. As populações indigenas, os negros, os homossexuais, as mulheres, os pobres, os periféricos têm conseguido, não sem dificuldades, figurar indispensáveis ao cenário leitor contemporâneo, realizando verdadeiras revoluções em termos do acesso, da produção, da circulação, do consumo e da leitura de materiais outrora desprezados.

É preciso ressaltar que o processo não está desprovido de contradições, notadamente, as disputas persistem, apesar das brechas e fissuras abertas em prol das mais diversas identidades e de um retrato mais inclusivo para o leitor, o que também the confere identidade leitora mais inclusiva. Segundo Tomaz Tadeu da Silva, (2006, p. 84) "o processo de produção da identidade oscila entre dois movimentos: de um lado, estão aqueles processos que tendem a fixar e a estabilizar a identidade; de outro, os processos que tendem a subvertê-la e a desestabilizá-las". E o cenário contemporâneo parece acirrar essa polarização, como nos lembra Christian Dunker ${ }^{8}$ em fala recente, porquanto vivenciamos uma dualização e um método de governo que se baseia na "produção de inimigos", alimentado discursos intolerantes (racistas, separatistas, sexistas, religiosos) que ultrapassam as querelas politicas entre direita/esquerda e desafiam a conhecida dinâmica que aproxima e/ou afasta os discursos, os enunciadores e os destinatários.

Os embates para o leitor do presente estão lançados, colocando em evidência sua diversidade (in)essencial e solicitando uma práxis pedagógica que se faça possibilidade efetiva de superação das práticas homogeneizadoras e excludentes. Onde os inessenciais? Lendo, produzindo o próprio material de leitura, forçando limites, quebrando barreiras, mas, para que os ganhos sejam permanentes e ampliados, a

As críticas podem ser lidas em vários sites que noticiaram o ocorrido em 2018, entre eles: https://g1.globo.com/politica/noticia/2018/11/og/bolsonaro-critica-questao-do-enem-2018-e-diz-que-em-2019-vai-tomar-conhecimento-da-prova-antes.ghtml. Acesso em: 3 abr. 2020.

8 Disponivel em: https://www.youtube.com/watch?v=4P5loLkXvMw. Acesso: 3 abr. 2020 
educação formal, pública e gratuita, precisa se fazer presente, fortalecida e qualificada.

\section{0 desafio de formar leitores em tempos de pós-verdade}

Ao caracterizar o tempo presente, não raro, o termo pós-verdade, registrado em 2016 pelo dicionário Oxford como a palavra do ano, é utilizado para significar a constatação de que fatos objetivos têm menos importância para o sujeito contemporâneo do que apelos à emoção e a crenças pessoais, o que coloca a verdade, como diz Dunker (2017, p. 11), num lugar sem "privilégios ou prerrogativas" e nos faz pensar que a assunção de tal estado torna imprescindivel considerar as formas como são processados conhecimentos, informações, saberes, e sobre como a educação e a formação leitora estão operando com tais circunstâncias, tendo em vista que é nas escolas que muito do conhecimento elaborado por nossas crianças e jovens ganha concretude.

Pensando que a "pós-verdade requer uma vida em estrutura de show e a sala de aula é o ensaio do espetáculo", Dunker (2017, p. 24) nos chama a atenção para o fato de que a escola é determinante para a separação entre o espaço privado e o público, concentrando a gênese da suspensão da verdade, de forma que precisa estar atenta à armadilha de reforçar a autoridade moral das tecnologias digitais, quando passa a atribuir relevância mais a quem está falando e seu carisma do que ao que está sendo falado; quando, na prática do trabalho em grupo e suas trocas, deixa passar lições de favorecimentos espúrios, manipulações; quando prega o privilégio da forma, do método, das técnicas em detrimento de qualquer substância.

Nesses termos, é preciso ratificar que o trabalho da escola não deve se confundir com ações realizadas em outras esferas da sociedade, posto que, na escola, firma-se a necessidade de que haja uma formação ampla e voltada a pilares fundacionais da existência humana, fato especificado no texto do relatório para a UNESCO ${ }^{9}$ da Comissão Internacional sobre Educação para o Século XXI, coordenada por Jaques Delors, que nomeia como pilares: aprender a conhecer, aprender a fazer, aprender a viver junto, aprender a ser. Em observância a demandas em torno de uma formação assim abrangente, que possa propiciar uma nova experiência comum, o trabalho pedagógico, não sendo apenas mais um agente de transmissão de informações e conhecimentos, vê-se cada vez mais desafiado a ser universo de criação, de autonomia, de pesquisa, de leitura, atuando como ponto de contradição e debate para as cooptações múltiplas que fazem as pautas mais interesseiras do dia.

Ao pensar nas consequências desse contemporâneo atravessado por ares de pósverdade, cada vez mais perceptivel com o amplo movimento das relações sociais midiáticas, fica patente o grande desafio das escolas e professores que, em pelo menos duas linhas de discussões gerais, precisam problematizar a formação leitora. O primeiro tópico refere-se ao entendimento da leitura como ato político, como direito, e incide sobre a necessidade de defendermos o ensino das linguagens frente ao mais novo ato de negligência dos poderes públicos e da sociedade em geral e que se configura por desconfianças, perseguições, censuras e ainda mais descrédito para professores e pesquisadores da educação, fato que reverbera com força na escolha de metodologias e materiais de leitura, mas principalmente, no caminho das interpretações, compreensões, inclusas aquelas ligadas às políticas identitárias. Exemplo disso foi o clima de desconfiança com o trabalho dos(as) professore(as)s, desse a campanha eleitoral de 2018 e seguindo a ascensão do atual governo, quando os alunos, pais e a sociedade em geral foram convocados, por autoridades (presidente do Brasil, ${ }^{10}$ deputados, ministros), a patrulhar, gravar, denunciar, divulgar aulas de professores que supostamente fizessem doutrinação ideológica.

\footnotetext{
9 Disponivel em: https://unesdoc.unesco.org/ark:/48223/pfo000109590_por. Acesso em: 1 abr. 2020.

10 Como exemplo, entre tantos, está disponivel nas redes uma fala do presidente atual incitando as filmagens: https://www.youtube com/watch?v=VAmNanaogTw. Acesso em: 3 abr. 2020.
} 
O patrulhamento gerou pontos de confronto na medida em que qualquer referência a questões étnicas, de gênero, de sexualidade ou até mesmo políticas passou a ganhar status de suspeição, apesar de trazer debates fundamentais para se pensar uma existência partilhada. Ora, qualquer assunto voltado às diferenças, às minorias, seja de caráter atual ou de cunho histórico, carrega uma discursividade passivel de ser interpretada sob a ótica do que chamam de doutrinação, porquanto mobilizam debates que podem ser direcionados a campos teóricos diferenciados e, muitas vezes, conflitantes, estando passiveis de serem encaminhados no sentido de acirrar a intolerância entre as pessoas, tanto nas instituições educativas quanto fora delas. Uma vez que os discursos de interdição são pautados pela ideia de identidade como igualdade, sem considerar a complexidade do que isso implica, podem exortar as pessoas a rejeitarem as diferenças, como se muitas das identidades que constituem o humano não devessem ter vez, voz, lugar; tudo supostamente justificado por um entendimento equivocado do que vem a ser o bem comum.

A pós-modernidade firmou a possibilidade de pensarmos as identidades em suas flutuações, mobilidade e processos de (des)identificações (HALL, 2006), sendo fato relevante para o fortalecimento de grupos que puderam, além de produzir vasto material de leitura, buscar textos mais condizentes com o interesse de suas pautas, elaborando e divulgando críticas de relevância impar para o trabalho de formação leitora nas escolas. No bojo desse olhar mais voltado às diferenças, muito se discutiu sobre o texto e suas configurações mantenedoras de uma visão preconceituosa da sociedade, não raro machista, racista, xenofóbica, desnudando uma histórica reprodução de estereótipos e preconceitos naturalizados.

Notadamente, o movimento no sentido de ampliar entendimentos acerca dos lugares identitários, inclusive no que tange à consciência de que a multiplicidade não apaga a possibilidade de choques, de divergências, de diálogos e negociações, é algo perceptivel quando as pessoas, em suas múltiplas constituições, vivenciam as próprias contradições subjetivas ou de interesses, traçando escolhas enunciativas, interpretativas ou ativas em relação à posição social, à religião, à cor, à sexualidade, por vezes, colocando-se mais favorável a uma ou outra identificação. Sem qualquer ideia de simplificação, sabe-se que as movimentações interpretativas contemporâneas pressupõem compreender as identidades como diferenças, no sentido de superar um grande gerador dos discursos intolerantes, a saber, uma concepção de igualdade que pressupõe marginalização e exclusão, funcionando como uma espécie de axioma inquestionável para justificar muitas formas de barbárie.

Um trabalho pedagógico condizente com tal complexidade, em observância às muitas identidades colocadas sob sua tutela, não pode deixar de trazer para a zona de interesses os "conhecimentos subjugados daqueles que foram marginalizados e abandonados, cujas histórias de sofrimento e esperança raramente são tornadas públicas" (MC LAREN, 1997, p. 266). Não no sentido de tolerar ou ilustrar uma ou outra circunstância, mas para ser alicerce basilar de um fazer pedagógico que problematize as diferenças, sem pregar a perseguição em nome de nenhuma moral. Há que se reconhecer o terreno de luta das identidades, potencializando seus traços mais favoráveis à construção de um futuro partilhado em respeito à diversidade.

Nesse sentido, faz-se pertinente considerar - que diz Tomaz Tadeu da Silva (2006) acerca da questão da identidade, tomando-a como um problema social, mas também como um problema pedagógico e curricular, na medida em que a escola não pode ignorar jamais a heterogeneidade do mundo que nos coloca constantemente em situações de encontro com o diferente, com o estranho, com o outro. A formação de uma identidade leitora, em sua interconexão com a formação das identidades em geral, precisa de uma pedagogia inovadora, que se faça terreno profícuo de superação de um único modelo virtual branco, heterossexual, rico 
para o leitor contemporâneo, que deve ser um sujeito politicamente engajado com as demandas politicas e sociais.

O segundo ponto a que pretendo dar destaque, é a vertiginosa oferta de textos convenientemente manipulados em sua construção linguisticodiscursivo-ideológica, sendo tecidos por linguagens arquitetadas para cooptar o leitor, e cuja compreensão encaminha, justamente, a satisfação daquilo que na definição do termo pósverdade faz apelo às crenças pessoais, à emoção, não raro, moldando a aceitação de pessoas pouco interessado em confrontar-se ou confrontar as muitas possibilidades que figuram disponiveis nos veículos de divulgação das informações e conhecimentos. Nesse ponto, mais uma vez é preciso ressaltar que a formação leitora de nossas crianças e jovens não pode ser opressão voltada a perpetuar desigualdades geradoras de submissão, pois o contexto contemporâneo, como bem definiu Agambem (2013), requer a coragem de mirar o escuro, de perceber os pontos apagados nas brechas e reentrâncias das luzes; ou como diz Galeffi (2019, p. 135), requer atitude radical de emancipação, à medida que pode exortar "um pensar livre de donos e comandantes".

A leitura, essa tarefa de compreender textos, discursos e mais amplamente as realidades, perpassa por arrebanhar dados dispersos no burburinho de cada dia, por isso mesmo, algumas questões fundamentais que poderiam alterar as compreensões possiveis a qualquer discurso podem passar despercebidas. Sob o véu das trivialidades, questões globais acerca da imigração, da conservação do meio ambiente, da dominação predadora do capital no mundo, das disputas políticas nacionais e internacionais, por exemplo, são moldadas a partir de determinantes simbólicos complexos, mobilizando múltiplas semioses (letra, imagem, som) colocadas em posição de neutralidade, mas que podem trazer determinantes cooptadores de difícil leitura para qualquer cidadão, mesmo os mais informados.
Cotidianamente, reverberam conceitos e preconceitos vinculados em linguagens expandidas e disparadas velozmente pelas mídias virtuais e demais veículos da informação, confundindo e dificultando uma compreensão ampla no mercado das ideias.

As manchetes ou posts mais comuns do dia podem trazer interesses dispersos para quem produz, lê ou replica nas redes, a exemplo das fake news ${ }^{11}$ divulgadas durante a campanha presidencial de 2018 no Brasil, com destaque para as que atacaram diretamente a educação, a escola, os professores, as identidades, tendo arrebanhando defesas sólidas e apaixonadas por muitos leitores, de niveis de formação diferenciados, apesar de serem facilmente desconstruidas pelo bom senso ou por uma simples busca na internet, o que pode ratificar o status contemporâneo de prevalência da pósverdade. Tais fake news circularam em textos de fácil e rápida leitura, materializando discursos temático-figurativos supostamente voltados aos cidadãos interessados em defender a moral e os bons costumes, mas reproduzindo cismas já bem marcados na sociedade brasileira e deixando patente a marginalização das diferenças em prol de um projeto político de extrema direita interessado em propagar ideias neoliberais de favorecimento do capital.

Assim, além das notícias maliciosas em relação aos profissionais da educação, mulheres, gays, negros, indigenas também figuraram como tema frequente em construções discursivas preconceituosas, inclusive por autoridades, o que se encontra divulgado amplamente nas mais variadas mídias, desde manchetes sensacionalistas até os jornais mais respaldados do Brasil. Os textos que circularam na sustentação da dualidade direita-esquerda encaminharam leituras destinadas a alimentar a já citada política do ódio que alimenta, não raro, muitas formas de intolerância.

Notadamente, a textualidade contemporânea compõe-se da circulação vertiginosa de discursos

\footnotetext{
11 A circulação de fake news no período das eleições presidenciais de 2018 tematizaram em muito a educação, a exemplo da noticia amplamente divulgada pelo candidato da direita de que as escolas públicas haviam recebido um kit gay distribuido em escolas públicas pelo Ministério da Educação, quando o presidenciável de esquerda, Fernando Haddad, tinha sido o ministro da pasta.
} 
complexos, fazendo um cotidiano perpassado por imagens, sons e palavras emaranhados que podem confrontar o leitor frente às próprias posições, tanto por informações que passam despercebidas na urgência frenética de mais um texto a ser compartilhado quanto pela impossibilidade de credibilidade das informações disponiveis ao consumo, justamente por atender a interesses diversos. A vontade de verdade, como a preconizou Nietszche (1999), ainda parece estar presente na ordem do dia, quando o assunto são os textos que chegam aos leitores cotidianamente e que podem se adequar ao horizonte de expectativas característico das bolhas de comunicação, principalmente nas redes midiáticas e seus lugares de poder, exercendo influência sobre outros discursos que se propagam, por sua vez.

O que talvez não seja mais possivel é a ideia de unicidade da verdade, na medida em que a mesma verdade pode se multiplicar indefinidamente, a partir de lugares diferenciados, demostrando abismos contrários do mesmo acontecimento/ fato e fazendo com que coexistam quantas verdades forem desejadas, contradizendo-se, mas arrebanhando, cada uma, seus discipulos, muitas vezes, interessados em algo que os contemple, ainda que isso represente endossar o ódio, a perseguição, a exclusão. Considerando Foucault (2009, p. 20), podemos dizer que seguimos e ignoramos "[...] todos aqueles que, ponto por ponto, em nossa história, procuraram contornar essa vontade de verdade e recolocála em questão contra a verdade, lá justamente onde a verdade assume a tarefa de justificar a interdição e definir a loucura".

Ora, se as verdades deixam de representar fidelidade, credibilidade, compromisso, as nãoverdades circulam aos montes e, como diz Tiburi (2017), simplesmente colam em contextos os mais impensáveis, fazendo a confirmação de que não há motivos para constrangimentos. Pode-se comprar tudo no mercado contemporâneo das comunicações, e mais, pode-se declarar qualquer barbárie nesse mesmo mercado, de forma que o trabalho pedagógico de leitura não pode fazer vistas grossas para uma realidade leitora em que versões de (não) verdades estão dispostas como em prateleiras para serem escolhidas ao bel prazer do cliente. Se há encaminhamento social para a validação da versão mais condizente com a interpretação que se deseja dar aos fatos e acontecimentos, cabe educação, à leitura, no universo do trabalho formativo, evocar a ética, a empatia, contribuindo para a superação da barbárie. Antônio Cândido (1995), ao escrever sobre literatura e direitos humanos, observou, como ponto a ser celebrado nos anos 90, a superação do elogio à barbárie, entretanto, o que hoje pode ser presenciado é o retrocesso a esse lugar de naturalização da injustiça, da exploração, da confirmação de um estado de exceção que achávamos estava sendo superado.

A contemporaneidade alavanca desafios para a práxis pedagógica, solicitando que a mesma não se deixe contaminar por discursos alheios aos objetivos da educação, de forma que as ações de leitura ficam convocadas a ser resistência direcionada à compreensão da palavra em suas interações com as outras linguagens, inclusive, com relativa ampliação da relevância dos determinantes contextuais, capazes de esclarecer pontos importantes para o entendimento dos discursos em suas múltiplas semioses. É preciso fortalecer uma concepção de leitura ligada a múltiplos recursos, linguagens, lugares de produção/circulação e suportes; uma concepção de leitura contextual que possa problematizar o emaranhado de variáveis recorrentes na atividade de produção, circulação e compreensão de textos e discursos, desde as ações mais cotidianas até as mais complexas formas de interpretação; enfim, é preciso assumir a leitura como possibilidade de ação e participação cidadã.

\section{Considerações finais}

Fazer do Brasil um país de leitores perpassa decisivamente pelo acesso a uma educação de qualidade e por uma melhor distribuição de renda para que mais gente possa permanecer nas escolas. O acesso amplo à leitura, se efetivamente realizado por grandes parcelas da 
população, significa mais poder aos cidadãos: maior capacidade para enxergar as contradições sociais, autonomia nas decisões, competências mais apuradas para chegar à superação das injustiças e desigualdades. Parece que esse ponto ficou claro, nas últimas décadas, com o abalo da crença segundo a qual o trabalho pedagógico representa uma ação neutra dentro da conjuntura social; o passo seguinte é fortalecer a autonomia e investir na qualidade das instituições educativas, para que as pessoas comprometidas com a educação possam continuar a desenvolver a sua função de crítica e transformação, como desafio emergente e urgente, e para que a população possa defender uma formação de qualidade para as próximas gerações, sem se deixar cooptar por falsas promessas de pessoas que nada entendem de educação, mas que utilizam seus discursos de ódio para gerar repetidas formas de intolerância. Precisamos questionar os mitos e reconhecer urgentemente que "nem todos os leitores são gente branca e bem vestida em casas elegantes e confortáveis" (ABREU, 2020, p. 9).

Diante do vasto mercado de discursos, o desafio para o leitor ainda é compreender, não apenas a palavra, o texto ou o discurso, mas as relações de produção, circulação e consumo; as armadilhas das representações; a expansão dos campos de saberes que se tocam e criam outras realidades, as próprias realidades que se erguem e se esvaem em cliques, bolhas e páginas fugazes. O desafio do ensino da leitura vai no mesmo sentido e precisa estar implicado com as alterações que ocorrem no meio social e político, sob pena de continuar engatinhando em matéria de textualidade, enquanto a internet e seus financiadores firmam-se como educadores anônimos de jovens e crianças em todo o país. Urge defendera autonomia do nosso sistema de ensino, a qualidade da educação pública, mas principalmente, o combate à ignorância, à intolerância.

A escola é um importante flanco de resistência, talvez um dos últimos, em um mundo configurado por textualidades a serem consumidas sem que necessariamente sejam compreendidas, por isso mesmo não pode permitir nenhuma forma de retrocesso pedagógico, nenhuma interferência política sem a qualificação mínima necessária para a ampliação da qualidade na educação. Se ainda é possivel formar um sujeito/leitor reflexivo, a escola não pode se fazer de rogada, tem que assumir seu compromisso apesar dos pesares.

\section{Referências}

ABREU, Márcia. Diferentes formas de ler. Disponivel em: https://www.unicamp.br/iel/memoria/Ensaios/ Marcia/marcia.htm. Acesso em: 01 abr. 2020.

ABREU, Márcia. Diferença e Desigualdade: preconceitos em leitura. In: MARINHO, Marildes (org.). Ler e Navegar: espaços e percursos da leitura. Campinas, SP: Mercado de Letras: Associação de leitura do Brasil, 2001.

AGAMBEN, Giorgio. O que é o contemporâneo e outros ensaios. Trad. De Vinicius Nicastro Honesko. Chapecó, SC: Argos, 2013.

BOURDIEU, Pierre. A leitura: uma prática cultural. In: CHARTIER, Roger (org.). Práticas da leitura. São Paulo: Estação Liberdade, 2001.

BEAUVOIR, Simone de. O segundo sexo: fatos e mitos. São Paulo: Difusão Europeia do Livro, 1970.

CANCLINI, N. Garcia. Culturas hibridas: estratégias para entrar e sair da modernidade. 4. ed. São Paulo: EDUSP, 2008.

CÂNDIDO, Antônio. Vários escritos. 3. ed. São Paulo, Duas cidades, 1995.

FOUCAULT, Michel. A ordem do discurso: aula inaugural no Collège de France, pronunciada em 2 de dezembro de 1970. 19. ed. Trad. de Laura Fraga de Almeida Sampaio. São Paulo: Edições Loyola, 2009.

DUNKER, Christian. Subjetividade em tempos de pós-verdade. In: DUNKER, Christian et al. Ética e pós-verdade. Porto Alegre/São Paulo: Dublinense, 2017.

Freire, Paulo. A Importância do Ato de Ler: em três artigos que se completam. 46. ed. São Paulo: Cortez, 2004.

Freire, Paulo. Pedagogia do Oprimido. 50. ed. São Paulo: Paz \& Terra, 2011

GALEFFI, Dante. Filosofar e Educar. Curitiba: Editora CRV, 2019

HALL, Stuart. A identidade cultural na pós-modernidade. 11. ed. Trad. Tomaz Tadeu da Silva e Guaracira Lopes Louro. Rio de Janeiro: DP\&A, 2006.

INEP. Relatório Brasil no PISA 2018 Versão preliminar. Disponivel em: http://download.inep.gov.br/acoes_internacionais/pisa/documentos/2019/relatorio_ PISA_2018_preliminar.pdf. Acesso em: 01 abr. 2020. 
INSTITUTO PAULO MONTENEGRO. Indicador de alfabetismo funcional INAF BRASIL 2018 Resultados preliminares: pesquisa gera conhecimento, o conhecimento transforma. Disponivel em: http://www.acaoeducativa.org.br/wp-content/uploads/2018/08/ Inaf2018_Relat\%C3\%B3rio-Resultados-Preliminares_ v08Ag02018.pdf. Acesso em: 01 abr. 2020

MC LAREN, Peter. A Vida nas Escolas: uma introdução à pedagogia crítica nos fundamentos da educação. Trad. Lúcia Pellanda Zimmer. Porto Alegre: Artes Médicas, 1997

NIETZSCHE, Friedrich. Obras incompletas. Trad. Rubens Rodrigues Torres Filho. São Paulo: Editora Nova Cultural Ltda, 1999.

ROJO, Roxane Helena Rodrigues; MOURA, Eduardo. Letramentos, mídias, linguagens. São Paulo: Parábola, 2019 .

SANTOS, Boaventura de Sousa. Esquerdas do mundo, uni-vos! São Paulo: Boitempo, 2018.

SILVA, Tomaz Tadeu da (org.). Alienígenas na sala de aula: uma introdução aos estudos culturais em educação. Rio de Janeiro: Vozes, 2006.

SLOTERDIJK, Peter. Crítica da razão cínica. São Paulo: Estação liberdade, 2012.

SOARES, Magda. Linguagem e escola: uma perspectiva social. São Paulo: Editora contexto, 2017.

TIBURI, Marcia. Pós-verdade, pós-ética: uma reflexão sobre delírios, atos digitais e inveja. In: DUNKER,

Christian et al. Ética e pós-verdade. Porto Alegre/ São Paulo: Dublinense, 2017.

\section{IImara Valois B F Coutinho}

Doutora em Letras pela Pontificia Universidade Católica do Rio Grande do Sul (PUCRS, Porto Alegre, RS, Brasil), Professora da Universidade do Estado da Bahia (UNEB) em Santo Antônio de Jesus (Campus V), BA, Brasil.

\section{Endereço para correspondência}

Ilmara Valois Bacelar Figueiredo Coutinho

Universidade do Estado da Bahia (UNEB)

Loteamento Jardim Bahia, s/n, 44.570-000

Santo Antônio de Jesus, BA, Brasil. 